\title{
ORIFICE DISEASES PROJECT - EXPERIENCE OF THE "HOSPITAL DAS CLÍNICAS" UNIVERSITY OF SÃO PAULO MEDICAL CENTER IN DAY-HOSPITAL OF ANORECTAL DISEASE
}

\author{
Sergio Carlos Nahas, Carlos Walter Sobrado Junior, Carlos Frederico \\ Marques, Antonio Rocco Imperiale, Angelita Habr-Gama, José Plínio \\ Souza Rocha and José Otávio Costa Auler Júnior
}

RHCFAP/2966

NAHAS, S.C. et al. - Orifice Diseases Project - Experience of the HCFMUSP in day hospital and anorectal disease. Rev. Hosp. Clín. Fac. Med. S. Paulo 54 (3): $75-80,1999$.

SUMMARY: The treatment of malignant or benign colorectal pathologies that require more complex management are priorities in tertiary hospitals such as "Hospital das Clínicas" University of São Paulo Medical Center (HCFMUSP). Therefore, benign, uncomplicated orifice conditions are relegated to second place. The number of patients with hemorrhoids, perianal fistulas, fissures, condylomas and pilonidal cysts who seek treatment at the HFMUSP is very great, resulting in over-crowding in the outpatient clinics and a long waiting list for recommended surgical treatment (at times over 18 months). The authors describe the experience of the HCFMUSP over an eight-day period with day-hospital surgery in which 140 patients underwent surgery. Data was prospectively taken on the patients undergoing surgery for benign orifice pathologies including age, sex, diagnosis, surgery performed, immediate and late postoperative complications, and follow-up. 140 patients operated on over eight days were studied. 68 were males (48.75\%) with ages ranging from 25 to 62 (mean 35.2 yrs.). Hemorrhoids was the most frequent condition encountered ( 82 hemorrhoidectomies, $58.6 \%$ ), followed by perineal fistula (28 fistula repairs, $20.0 \%$ ). The most common complication was headache secondary to rachianesthesia occurring in 9 patients $(6.4 \%)$. One patient $(0.7 \%)$ developed bleeding immediately PO that required reoperation. Mean follow-up was 104 days. Day-surgery characterized by quality care and low morbidity is feasible in tertiary public hospitals, permitting surgery for benign orifice pathologies on many patients within a short period of time.

DESCRIPTORS: Day-hospital. Day-clinic. Orifice surgery, cost-benefit analysis.

The treatment of benign orifice conditions (hemorrhoids, perianal fistulas, chronic anal fissures, pilonidal cysts and anal condylomas) is relegated to second place in tertiary public hospitals where priorities are geared to more complex pathologies (neoplasias, inflammatory diseases, etc.). Nevertheless an excessive number of patients flock to the hospital resulting in throngs in the out-patient clinics and long waiting lists for definitive treatment (average wait of 18 months).

Day-hospital management of benign orifice pathologies has been confirmed as the most cost-effective approach, and at the same time is safe and effective, characterized by low morbidity ${ }^{1-7}$.

The problem of orifice disease, besides being painful and disabling, is costly and detrimental to the country. The authors describe the solution adopted by the "Hospital das Clínicas" University of São Paulo

Coloproctology Division, "Hospital das Clínicas, Faculdade de Medicina da Universidade de São Paulo", Brazil.
Medical Center (HCFMUSP) to solve the problem of overcrowding and long waiting periods for surgical treatment of benign orifice conditions in public hospitals. Our solution addresses this problem in an up-to-date manner, efficiently, and safely.

\section{PATIENTS AND METHODS}

The Orifice Diseases Project consisted of eight surgical sessions in which the surgical center of the Central Institute of the HCFMUSP 
activated three operating rooms with nurses, aides, and orderlies for the Coloproctology Division. Two senior surgeons and five residents were responsible for the operations. The Anesthesiology Division scheduled three senior anesthetists and three residents for each one of the Saturdays. The number of procedures for the Project day was limited to 17 .

Surgery was performed first on patients programmed for same day discharge, followed by those who would be hospitalized overnight. Hemorrhoidectomy deserved special attention, both because of major risk of immediate PO bleeding (confirmed by reoperation in one case) as well as for better pain control ${ }^{16}$. Therefore, a 23hour schedule was adopted, whereby the patient was hospitalized overnight and was discharged the next morning after medical rounds.

Before going home, the patients were checked by the anesthetic and surgical teams. The patients received written guidelines about postoperative care of the wound, analgesia, diet, and first evacuation.

Patients on our ward awaiting preoperative preparation were given leave on the weekend when the hospital functions with a skeleton crew, freeing beds without delaying treatment.

One-hundred and forty patients with benign orifice disease underwent surgery during eight weekends from April to September 1998.

To determine eligibility for the study, a case history of the patient's complaints was taken, and a complete physical and proctological examination were performed on each patient (including rigid rectosigmoidoscopy).

Patients were selected by age (under 60), surgical risk and anorectal pathology, with the objective of early discharge. Based on the American Society of Anesthesiology (ASA) ${ }^{8}$ classification of surgical risk, patients in ASA I or II were chosen. More severe anorectal conditions were excluded, i.e., complex fistulas, stric- tures, incontinence, suspicion of neoplasia or manifestations of inflammatory disease.

The data was recorded prospectively, from the consultation prior to surgery until the last return to the clinic. Factors recorded were age, sex, surgical risk, pathology, technique utilized, hospitalization, time from diagnosis to definitive treatment, immediate and late complications, and the outpatient follow-up.

Initially, those with hemorrhoids were to spend the night in the hospital, and they would probably be discharged on the following morning after medical rounds.

Patients with perianal fistula, chronic anal fissure, pilonidal cyst and condyloma of the anal canal were informed that they would probably be discharged late in the afternoon of the procedure, after the physician's check-up. These subjects were to appear at the HCFMUSP on the morning of the operation with someone who would be responsible for their return home. They were informed of the necessity of fasting after 22:00 o'clock and of an enema the night before (material supplied free of charge).

Patients with hemorrhoids were selected for the program if they displayed advanced class III or IV disease, recurrence, or dissatisfaction with the previous conservative methods used.

Patients with either simple or complex perianal fistulas were chosen. Patients with fistulas with other etiologies known to be non-infectious were excluded.

Patients with chronic anal fissure not responding to conservative clinical treatment, with hypertonia on proctological examination and eliminating inflammatory causes were included in the project.

Patients with pilonidal cysts were accepted without the aforementioned restrictions.

In HIV negative cases, extensive condylomatous lesions of the anal canal, refractory to topical treatment, were managed surgically in the project.

Epidural block anesthesia was employed in all subjects: the technique (peridural or rachianesthesia), the drug, and the crystalloids employed during the procedure were left up to the criteria of the Division of Anesthesiology.

On discharge, patients were given printed prescriptions for analgesics for pain-relief, including their dosing times. They were also given guidelines regarding sitz baths, guidelines for a diet rich in fibers, and mild laxatives. Patients treated for pilonidal cysts received more detailed orientation regarding dressings. They were all oriented verbally and in writing about care of the surgical wound, dressings, and the first evacuation. In case of severe pain, fever or uncontrollable bleeding they were instructed to go immediately to the emergency surgery center of the HCFMUSP, where a physician taking part in the project would be located.

The first outpatient return was scheduled for the third or fifth PO day, when the patient was questioned regarding pain, fever, bleeding, and evacuation. Then the wound was inspected. Digital examination was not carried out, but the perianal region was palpated in cases of more severe pain. When indicated, digital examination was accomplished on the tenth PO day. Similar examinations were conducted at subsequent return visits scheduled for one, two, four, eight and twelve weeks after surgery.

\section{RESULTS}

During eight Saturdays, from April to September 1998, 140 patients with benign orifice disease underwent surgery.

Mean age was 35.2 years (25-62), with 71 females $(50.71 \%)$. All 
patients were ASA 1. Mean waiting time from surgical indication to realization in the patients in the first cycle was 18 months and in the last cycle 30 days.

Mean outpatient follow-up was 104 days, ranging from 90 to 120 days. In the $82(58.57 \%)$ patients with hemorrhoids, $73(89.0 \%)$ open and five Ferguson hemorrhoidectomies were performed, and four utilized a mixed technique.

Twenty-eight $(20.0 \%)$ suffered from perianal fistula and fistulectomy, requiring curettage and exposition of the fistulous bed for the majority. In five (18.0\%) it was decided intraoperatively to accomplish the fistulectomy in two stages. In these cases, a prolene seton 2 was placed in the fistulous bed after its identification with a stylette and verifying significant involvement of the external anal sphincter. Five patients $(18.0 \%)$ required overnight hospitalization because of the extensive debridement.

Among the 12 (8.6\%) patients with chronic anal fissure with hypertonia of the sphincter, six were managed by fissurectomy and lateral internal sphincterotomy under direct vision, the other six with submucous lateral internal sphincterotomy.

All eight (5.7\%) subjects with pilonidal cyst were managed by incision and curettage.

The ten patients $(7.1 \%)$ with perianal condyloma and involvement of the anal canal had their lesions electrocauterized.

The chief immediate complication was post-rachianesthesia headache occurring in nine cases $(6.4 \%)$, so that one required a "blood patch."

One patient $(0.7 \%)$ that underwent closed hemorrhoidectomy required reoperation for control of immediate PO bleeding. There were no other cases of immediate or late PO bleeding nor readmissions as a result of the operations.
With the exception of one patient $(0.7 \%)$, that was managed with outpatient anal dilatation, there have been to date no other complaints regarding difficulty of evacuation or incontinence for gases or feces.

The cost of surgery for a hospitalized patient compared to a day clinic one was US\$570.00 for the former and US\$390.00 for the latter ${ }^{21}$. The minimum savings calculated for 52 patients operated ambulatorily was US $\$ 9,300.00$. If the cost of the patients on the 23 hour hospitalization program is added to this figure, there is a saving of over US $\$ 10,000.00$.

\section{DISCUSSION}

The management of benign orifice conditions in tertiary public hospitals in Brazil is unsatisfactory. In April 1998, patients in the HCFMUSP with indication for definitive treatment were on a waiting list for about 18 months.

The delay is the result of a public health system that does not measure up to the necessities of the population of a megacity such as São Paulo. Here, a large part of the poorer population still seek treatment at tertiary centers for the simplest to the most severe health problems. A huge number of patients with simple pathologies flock to a place designated to treat complex diseases, resulting in a breakdown and delay in the outpatient clinics whose surgical schedules are overcrowded.

The wards and surgical centers cannot take care of this demand, requiring selection of patients for hospitalization of elective surgical procedures. Patients with severe, consumptive, and complex diseases have preference compared to those with benign illnesses particularly affecting patients with orifice diseases.
In spite of their "simplicity", benign orifice disorders can be very painful $1^{1,10,11}$, especially during periods of exacerbation of symptoms, momentarily incapacitating the patient, and forcing him to resort to expensive palliative treatments, in addition to provoking great anxiety regarding his health.

When he seeks treatment at the tertiary public hospital, the necessary care is unavailable, and the patient is treated palliatively with medicines that the patient often supplies. If the number of patients who cannot wait and go to other hospitals is added to the unnecessary return to the outpatient clinic, the loss in time and money is great.

With this problem in mind, the Coloproctology Division of the FMUSP, stimulated by the example of other projects, created the Orifice Diseases Project. Following a global trend $^{1-7,12}$ of controlling hospital costs, with preference for minor procedures that are less expensive and have lower morbidity, the treatment of benign orifice diseases is largely ambulatorial ${ }^{1,6,9-15}$, reserving hospitalization for more advanced illnesses, for anxious, or for clinically severe patients who require more intense PO care $^{16}$. The Orifice Diseases Project conforms to this outpatient trend. Surgical management was indicated in cases of advanced disease or recurrence or dissatisfaction with outpatient treatments (i.e., rubber band ligations). The few patients hospitalized resulted from intraoperative decisions, requiring preparation of the system (reservation of a bed).

The rate of PO bleeding and stenosis was low compared to the literature (Table 1) $)^{1-7,17-19,21}$. Anesthesia was the principal complication, within acceptable levels of the medical literature ${ }^{18}$. No patient was rehospitalized. There were no infectious complications, nor up to the 
Table 1 - Hemorrhoidectomy complications

\begin{tabular}{lll}
\hline Classification & Incidence \%(Project) & Incidence \% Literature \\
\hline & & \\
ACUTE & - & 4.3 to 15.9 \\
Pain $^{16,17}$ & - & 2 to 4 \\
Bleeding (Clinical Manage.) $^{17-19}$ & 0.71 & 0.8 to 1.3 \\
Bleeding (Surgical Manage.) $^{17-21}$ & 6.42 & 2.1 to 32 \\
Urinary retention $^{18,21}$ & - & $<1$ \\
Hemorrhoidal thrombosis $^{21}$ & - & $<1$ \\
Wound infection" $^{21}$ & - & $<1$ \\
Fecal impaction $^{21}$ & & \\
& & \\
CHRONIC & - & 6 \\
Plicomas $^{21}$ & 0.71 & 1 \\
Anal stricture & & \\
Anal fissure $^{21}$ & - & $<0.4$ \\
Anal incontinence & & \\
Anal fistula & & \\
"Recurrent hemorrhoid"21 & - & $<1$ \\
\hline
\end{tabular}

present time incontinence secondary to the surgical procedures. Follow-up was a mean of 104 days ranging between 90 and 120 days.

The reduction in time between the diagnosis and the surgery confirms the efficiency, speed, and intensity of the project. Previously in our Service, eight patients/month underwent surgery, (96 patients over a year). On the eight Saturdays, 140 patients underwent surgery. Waiting time dropped from 18 months to two weeks.

The number of orifice surgeries performed by the residents also rose considerably; they had the opportunity to perform or assist in four or five similar surgeries in one day, resulting in better familiarity with and improved training in the treatment of orifice disease ${ }^{20}$.
There is no description in the literature of such a volume of orifice surgeries over a short period in a large public hospital. The dedication of the assistants of the Coloproctology Division, who voluntarily left their homes on weekends and received no payment in return for taking part in the project, is noteworthy. The same is true of the assistant physicians of the Anesthesiology Division, the nurses, nurses aides, and orderlies who did not receive any compensation for their participation in the project.

\section{CONCLUSION}

The Orifice Diseases Project demonstrated that it is a safe and effi- cient program, an excellent option for treatment of orifice conditions, with low morbidity and a good cost/benefit ratio for a tertiary public institution such as the HCFMUSP.

\section{AKNOWLEDGEMENT}

We wish to thank the Executive Board of the "Hospital das Clínicas", University of São Paulo Medical Center, the Directors of the Surgical Center (Prof. Brasiliense Fusco and chief nurse João Possari), the Anesthesiology Division (Prof. José Otávio Costa Auler Júnior) and the Nursing Division whose efforts and good will permitted the realization of this program. 
NAHAS, S. C. e col. - Projeto doenças orificiais experiência do HCFMUSP em hospital-dia e doenças anorretais. Rev. Hosp. Clín. Fac. Med. S. Paulo 54 (3): $75-80,1999$.

RESUMO: O tratamento das patologias colorretais malignas ou benignas, que necessitam tratamento com maior grau de complexidade são prioridades em hospitais terciários, como é o Hospital das Clínicas da Faculdade de Medicina da Universidade de São Paulo (HCFMUSP), permanecendo assim as patologias orificiais benignas em um segundo plano. Todavia devido à sua característica assistencial, o número de pacientes que procuram o HCFMUSP por doença hemorroidária, fístulas perianais, fissuras, condilomas e cistos piloni- dais é muito grande, resultando na hipertrofia dos ambulatórios e lentidão para o tratamento cirúrgico preconizado (às vezes um ano e meio). Os autores descrevem a experiência do HCFMUSP durante oito dias com o atendimento tipo hospital-dia em que 140 pacientes foram atendidos e submetidos a intervenções cirúrgicas.

Foram anotados prospectivamente os dados de paciente submetidos a tratamento cirúrgico para patologias orificiais benignas quanto a idade, sexo, diagnóstico, tratamento cirúrgico realizado, e complicações pós operatórias imediatas e tardias e tempo de seguimento ambulatorial.

Foram estudados 140 pacientes, operados em oito dias, sendo $68(48,75 \%)$ homens e a idade variando entre 25 e 62 anos (média de 35,2 anos). A doença hemorroidária foi a patologia mais freqüente, com 82 doentes operados $(58,57 \%)$, seguido pela fístula perineal com $20,0 \%$ dos casos operados. A complicação mais freqüente foram as anestésicas com a cefaléia pós raquianestesia ocorrendo em nove pacientes $(6,42 \%)$. Um paciente $(0,71 \%)$ apresentou hemorragia no $\mathrm{PO}$ necessitando reoperação para hemostasia. O tempo médio de seguimento foi de 104 dias. O uso do conceito hospital-dia em serviços públicos terciários é factível, com a possibilidade de atendimento de grande quantidade de pacientes com patologias orificiais benignas, em curto espaço de tempo, com qualidade e baixas taxas de complicações.

DESCRITORES: Hospital-dia. Cirurgia orificial.

\section{REFERENCES}

1. HYMAN, NH - Anorectal disease: how to relieve pain and improve other symptoms. Geriatrics, 1997; 52: 75-91.

2. SIAS F, LICHERI S, SECCI L et al. - Chirurgia ambulatoriale: stato attuale e prospettive. Ann Ital Chir, 1996; 67:111-115.

3. ROBINSON AM, SMITH LE \& PERCIBALLI JA - Outpatient hemorrhoidectomy. Mil Med, 1990; 155: 299-300.

4. LACERDA-FILHO A \& CUNHA-MELO JR - Outpatient haemorrhoidectomy under local anaesthesia. Eur J Surg, 1997; 163: $935-940$.

5. CARAPETI EA, KAMM MA \& MAC DONALD PJ et al. Double blind randomized controlled trial of effect of metronidazole on pain after day-case haemorrhoidectomy. Lancet, 1997; 351: 169-172.

6. FERGUSSON JA \& MACKEIGAN JM - Hemorrhoids, fistulae and fissures: office and hospital management-a critical review. Adv Surg, 1978; 12:111-153.

7. HO Y, LEE J, SALLEH I et al. - Randomized controlled trial comparing same-day discharge with hospital stay following haemorrhoidectomy. Aust N Z Surg, 1998; 68: 334-336

8. GOLDMANN L - Letter. N Eng J Med, 1978; 298:340.

9. DENNISON A R, PARASKEVOPOULOS JÁ, KERRIGAN DD et al. - New thoughts on the aetiology of haemorrhoids and the deve- lopment of non-operative methods for their management. Minerva, 1996; Chir 51: 209-216.

10. DOZOIS R \& PHLLIPS R - Surgery of the colon and rectum. London, Livingstone, 1997 p. 465-475.

11. KUMAR D - Perianal and anorectal conditions. Br J Hosp Med, 1996; 55: 464-7.

12. SINGLETON R.J, RUDKIN GE, OSBORNE GA et al. Laparoscopic cholecystectomy as a day surgery procedure. Anaesth Intens Care, 1996; 24: 231-236.

13. BAYER I, MYSLOVATY B \& PICOVSKY BM - Rubber band ligation of hemorrhoids. Convenient and economic treatment. J Clin Gastroenterol, 1996; 23: 50-52.

14. COHEN Z - Alternatives to surgical hemorrhoidectomy. Can J Surg, 1985; 28: 230-231.

15. BOGHOSSIAN P, MILES WFA, GUDGEON AM et al. - The rapid access proctologic clinic: an appraisal of one year's experience. $\mathbf{B r}$ J Gen Practice, 1996; 46: 741-742.

16. GAWENDA M \& WALTER M - Die operative Therapie des fortgeschrittenen Hämorrhoidalleidens - Ist ein Eingriff auf tageschirurgischer Basis möglich? Chirurg, 1996; 67: 940-943. 
17. EU KW, TEOH TA, SEOW-CHOEN F et al. - Anal stricture following haemorrhoidectomy: early diagnosis and treatment. Aust $\mathbf{N} \mathbf{Z}$ Surg, 1995; 65: 101-103.

18. HOSH SB \& KNOEFEL WT - Treatment of piles/ prospective, randomized study of Parks vs Milligan-Morgan haemorrhoidectomy. Dis Colon Rectum, 1998; 41: 159-164.

19. SEOW-CHOEN F, HOY, ANG H et al. - Prospective, randomized trial comparing pain and clinical function after conventional scissors excision/ligation vs. Diathermy excision without ligation for symptomatic prolapsed hemorrhoids. Dis Colon Rectum, 1992; 35: 1165-1169
20. NICHOLLS RJ - So you want to train in coloproctology. Br J Hosl Med, 1997; 57: 571-573.

21. SOBRADO CW, BRINGEL RW \& NAHAS SC - Tratamento cirúrgico da doença hemorroidária. In: MAGELA G- Coloproctologia: tratamento clínico e cirúrgico. Rio de Janeiro. G. Rewinter, 1998. v.3, c.115.

Received for publication on the 18/12/98 